\title{
Collaborative Development of Textile and Apparel Curriculum Designed to Foster Students' Global Competence
}

By: Nancy Hodges, Kittichai Watchravesringkan, Elena Karpova, Jane Hegland, Gwendolyn O’Neal, Sara Kadolph

This is the peer reviewed version of the following article:

Hodges, N., Watchravesringkan, K., O’Neil, G., Hegland, J., Karpova, E., \& Kadolph, S. (2011). Collaborative development of curriculum designed to foster global competence: A report on project products, results and outcomes. Family and Consumer Sciences Research Journal, 39(4).

which has been published in final form at

http://dx.doi.org/10.1111/j.1552-3934.2011.02073.x

This article may be used for non-commercial purposes in accordance with Wiley Terms and Conditions for Use of Self-Archived Versions. This article may not be enhanced, enriched or otherwise transformed into a derivative work, without express permission from Wiley or by statutory rights under applicable legislation. Copyright notices must not be removed, obscured or modified. The article must be linked to Wiley's version of record on Wiley Online Library and any embedding, framing or otherwise making available the article or pages thereof by third parties from platforms, services and websites other than Wiley Online Library must be prohibited.

\section{Abstract:}

Textile and apparel industry professionals must be capable of dealing with cultural differences and diverse perspectives on a multinational scale. To address the challenges involved in educating students for the global industry workforce, a 3-year collaborative project was conducted through partnerships between faculty at three U.S. universities and five universities in Thailand, Australia, and Russia. The project was designed to create learning modules based on real-world industry issues to foster global competence among students in textile and apparel programs. Tested in existing courses, module effectiveness was assessed using pre- and post-tests that included closed- and open-ended questions designed to measure students'“cultural intelligence" as an indication of global competence. Results suggest that exposure to the modules helped to improve students' global competence. However, further development and testing of the modules is needed to include students in programs and countries in addition to those represented by this study.

Keywords: cultural intelligence | global competence | learning modules | textiles and apparel 


\section{Article:}

Understanding manufacturing and distribution processes in the textile and apparel industries requires an in-depth knowledge and consideration of the complexities of commerce, labor, and trade practices unique to countries everywhere. International trade agreements, coupled with increasing global competition have forced the U.S. textile and apparel industries to re-define and reposition themselves to remain competitive. Over the last 25 years, these industries have globalized most, if not all, of their operations in manufacturing and production (Hodges \& Lentz, 2010; Norris, 2003). Movement of these facilities to off-shore locations, whether in Central and South America, the Caribbean Basin, Eastern Europe, or Asia, has resulted in more than an increased earning capacity. With this shift has come the challenge of production that spans cultural boundaries (Rivoli, 2009). As labor-intensive industries, such decisions often require forging long-term partnerships with foreign companies to remain viable within the global economy (Cammett, 2006; Oh \& Suh, 2003).

As these industries become increasingly globalized, to remain competitive the "face" of the U.S. workforce has had to change. Its professionals must be capable of dealing with cultural difference and diverse perspectives on a multinational scale, as they help to manage a supply chain process that often spans the globe (Hodges \& Karpova, 2006; Scott, 2006). This professional must be able to work within an evolving industry in the midst of what appears to be a prolonged period of globalization (Mittlehauser, 1997). University students preparing for these industries must acquire the requisite knowledge and skills to function successfully within this dynamic global environment. Faculty must be able to provide learning opportunities to ensure that students are prepared to enter this workforce and achieve their career goals.

Particularly important are experiences that provide students with exposure to perspectives of individuals within countries or cultures beyond U.S. borders. Currently there are few opportunities available in higher education specific to textile and apparel students, beyond study abroad, that provide them the necessary exposure to cultural difference in preparation for employment within the increasingly global context of the industry. Also needed are measures to ensure that relevant issues stemming from globalization of the U.S. industry are dealt with in the curriculum. This article presents the results of a project that involved the development of learning opportunities designed to infuse a global industry perspective into the textiles and apparel classroom. Moreover, the opportunities were tested to assess the extent to which they fostered students' global competence.

\section{Background}

Given the need for an industry workforce that can operate across cultural boundaries, a collaborative project was developed that involved faculty at three universities in the United States (University of North Carolina at Greensboro, Iowa State University, and South Dakota State University) and faculty at universities in Russia (St. Petersburg Academy of Service and 
Economy and Kostroma State Technological University), Thailand (Burapha University and Kasetsart University), and Australia (Royal Melbourne Institute of Technology). By creating linkages between university programs in these countries, the project created a global framework that would better foster the globalization of teaching and learning. The countries represented by the project are ideal in that each has established industries in the manufacturing and distribution of textile and apparel-related products (DesMarteau, 2005; Hanzl-Weiss, 2004), and each is home to postsecondary academic programs in textiles and apparel.

The primary goal of the project was to work together to create learning opportunities that foster global competence among students in textile and apparel programs. A second goal of the project was to assess the effectiveness of such learning opportunities when introduced within the textile and apparel curricula. The assessment was designed to examine the extent to which exposure to the modules enhanced students' global competence by increasing their level of "cultural intelligence" (Thomas, 2006).

In this article, the term globalization in the context of the academic institution is defined as the process of integrating global learning into the curriculum (Harari, 1989). Globalization, when referring to the operations within the textile and apparel industries, is defined as the process by which products and services are produced and used across national borders (Dickerson, 1999). For both academia and industry, globalization is used with the understanding that it is a comprehensive term referring to the emergence of a global society in which economic, political, environmental, and cultural issues have significance beyond a single nation.

\section{Global Competence}

In Educating for Global Competence, the American Council on Education states that "America's future depends upon [its] ability to develop a citizenry that is globally competent" (Commission on International Affairs, 2000). According to Harari (1992), the role of the academic institution in ensuring the development of such a citizenry is critical:

"The rationale for the globalization of undergraduate education must of necessity take us back to the meaning we give to liberal education and liberation of the mind. Whatever our definition might be it is clear that acquiring global awareness and an understanding of the diversity of cultures and societies on our planet has to be considered an integral part of education (p. 53)"

Global competence requires respect for and understanding of diverse experiences and points of view (Hunter, White, \& Godbey, 2006). The American Council on International Intercultural Education recently put forth the following definition as a benchmark for globalizing curriculum: 
Global competency exists when a learner is able to understand the interconnectedness of peoples and systems, to have a general knowledge of history and world events, to accept and cope with the existence of different cultural values and attitudes, and indeed, to celebrate the richness of this diversity (American Council on International Intercultural Education, 2005)

However, the need for global competence does not pertain only to the process of higher education; it is also germane to its outcomes. Specifically, graduates are leaving universities to enter a workforce that is inherently global in nature. Fostering a comprehensive understanding of the global dimensions of textile and apparel manufacturing and distribution practices is imperative to ensure that graduates are capable of leading the industry into the future. For the purposes of this project, we posited that the development of global competence begins in the classroom, where students' understanding can be enhanced through the introduction of issues and challenges faced by industry in working on a global platform.

More institutions of higher education have placed globalization among their top priorities. According to Knight (1997), the top three reasons for globalizing teaching and research across U.S. campuses are: (i) to prepare students who are internationally knowledgeable and interculturally competent, (ii) to maintain competitiveness, and (iii) to achieve international standards. By working to establish opportunities for global learning, the focus of the 3-year project was to create teaching resources created by and through a multinational collaborative framework that would help students develop the global competence required by professionals in the textile and apparel industries.

\section{Cultural Intelligence}

To assess whether the project fostered students' global competence, an instrument was used to measure students'"cultural intelligence" before and after exposure to the learning opportunities. Cultural intelligence (CQ) is a relatively new concept, introduced into the international business literature in the early 2000s (cf., Earley, 2002; Earley \& Ang, 2003). CQ is built on the attitude, value and behavior characteristics that arise out of culture, combined with the concept of intelligence. CQ is a type of social intelligence that allows a person to be socially effective in multiple and varied cultural settings with different cultural norms (Brislin, Worthley, \& Macnab, 2006). It requires an individual be effective across cultures, not just within them (Brislin et al., 2006; Ng \& Earley, 2006; Thomas, 2006; Thomas \& Inkson, 2004). In essence, CQ is "the ability to interact effectively with people who are culturally different" (Thomas, 2006, p. 78).

Cultural intelligence is more than interacting with those who are culturally different. It requires the capability to adapt to and shape one's reactions in a new cultural setting. The culturally intelligent person acquires CQ from social learning: "Social learning involves attention to the situation, retention of the knowledge gained from the situation, reproduction of the 
behavioral skills observed, and finally receiving feedback (reinforcement) about the effectiveness of the adapted behavior" (Thomas, 2006, pp. 89-90). Social learning improves an individual's CQ because they are paying attention to and appreciating critical differences between their own culture and that of others.

Thomas and Inkson (2004) developed a conceptual model of CQ based on three components: knowledge, mindfulness, and behavior. For persons to be deemed culturally intelligent they must have: (i) the knowledge to understand cross-cultural phenomena, (ii) the mindfulness to observe and interpret particular situations, and (iii) the skill of adapting behavior to act appropriately and successfully in a range of situations (Thomas, 2006; Thomas \& Inkson, 2004). Researchers agree that CQ is developed and learned over time through intercultural interactions. Thomas (2006) developed a conceptualization of the stages in CQ development: (i) reactivity to external stimuli, (ii) recognition of other cultural norms and motivation to learn more about them, (iii) accommodation of other cultural norms and rules in one's own mind, (iv) assimilation of diverse cultural norms into alternative behaviors, and (v) proactivity in cultural behavior based on recognition of changing cues that others do not perceive (highest CQ level; Thomas, 2006). According to Thomas, the stages of CQ development build on one another. As persons increase their capabilities, they increase their overall CQ.

\section{Curriculum Development: Process and Products}

To address the objectives of the project, learning opportunities were created that were tailored specifically to textile and apparel curricula. To create these opportunities, curriculum development occurred in three phases: (i) data collection, (ii) creation of learning modules, and (iii) module testing and assessment. Phase I involved data collection and analysis among and across the three U.S. institutions. Secondary data were collected on the industry within each country, including import and export data, employment figures, industry segmentation, corporate culture, laws pertaining to the industry in the country, and industry strategy. Industry profiles specific to each country were compiled using this data.

Then the research team conducted interviews with industry professionals and government officials within Russia, Thailand, and Australia. Interviewees were recruited through a snowball sampling technique that relied on the referral method (Biernacki \& Waldorf, 1981), wherein faculty at the U.S. and partner universities contacted industry and government representatives to request interviews. A total of nine interviews were conducted in Russia, eleven in Thailand, and six in Australia. All interviews were conducted at the primary business location and lasted between 1 and 3 hrs, depending on the setting and the availability of the interviewees. Interviews were also conducted with industry professionals in different areas of the United States. Using the referral method again, a total of 11 U.S. companies were contacted and interviewed, representing a range of different types of companies that graduates might work for, from small apparel retailers to multinational apparel manufacturing and distribution companies. Interviews were conducted at the company and lasted between 3 and $4 \mathrm{hrs}$ each. 
Discussion with industry professionals focused on global issues that they face on a day-to-day basis. Questions were developed based on identification of similar issues that arose across the country-specific industry profiles. Specific questions included: What strategies are being implemented to develop the industry in this region and globally? What resources do the industries need to accomplish their goals? How do you envision apparel, textile, and/or retailing companies changing in the next 5-10 years? How are you preparing for these changes? Participants were also asked to share their perceptions of the skills and abilities needed by students to deal with these issues as future industry professionals. For example, what do you think a well-rounded graduate would look like? and, What special characteristics do you look for when hiring new graduates? Specific attention was paid to the extent to which industry in each of the countries values graduates capable of working on a global platform.

Focus groups with faculty and students at universities in each of the four participating countries were also conducted. Focus group participants were asked to share their views on the need for globally based learning opportunities and projects that integrate real-world issues and challenges faced by the industry. Questions asked of faculty and students were developed by the project faculty based on the issues identified in the secondary data, industry profiles, and literature on global competence, and include: Do you feel prepared to teach students the current skills required of the global industry? Why or why not? What areas of your curriculum do you change to keep up with industry trends? and How do you ensure your students are exposed to and learn to manage cultural difference? Students were asked questions like: Do you think you are learning what you need to know to succeed in a global industry? What skills do you think are absolutely necessary to be successful in this industry? and, Do you feel that you are well prepared to enter the industry job market?

A total of 44 industry, government, student, and faculty audio-taped interviews and focus groups were conducted in the four countries. Findings from the interviews and focus groups were used to inform Phase II, which involved the development of the learning opportunities designed to foster global competence. Educational materials were created that included compilations of readings, videos, and case studies based on Phase I data. Collaborative projects were developed that teamed U.S. students and students at the partner international universities and were designed to reflect similar kinds of team-based activities that occur in the industry.

Learning modules were developed that integrated these collaborative projects and materials. A total of eight web-based modules were created around key issues that emerged from the research and targeted a related course or content area within the textile and apparel curriculum, including: (i) sourcing, (ii) international trade, (iii) company strategy, (iv) branding, (v) intercultural communication, (vi) small and medium-sized enterprises, (vii) product development, and (viii) the retail landscape. Specific issues currently faced by the industry (e.g., supply chain management, manufacturing and labor laws, import and export regulations, etc.) were dealt with through active learning activities built into each module. Module activities were designed to be completed in class or online. Modules included teaching resources, such as PowerPoint lectures, current reading lists, quizzes, assignments, links to pertinent videos and 
websites, and in-class activities. Methods used to assess student learning included quizzes, essays, in-class discussions, short answer response, research papers, and collaborative projects. Table 1 describes the focus and content of the modules.

Table 1: Module Type, Content Focus, Number of Activities, Duration, Test Course, and University

\begin{tabular}{|c|c|c|c|c|c|}
\hline Module & Content Focus & $\begin{array}{c}\text { Number of } \\
\text { Activities }\end{array}$ & $\begin{array}{l}\text { Duration } \\
\text { (weeks) }\end{array}$ & Test Course & University \\
\hline Sourcing & $\begin{array}{l}\text { Managing the } \\
\text { global sourcing } \\
\text { process }\end{array}$ & 6 & 9 & Global sourcing & UNCG \\
\hline $\begin{array}{l}\text { International } \\
\text { trade }\end{array}$ & $\begin{array}{l}\text { Dynamics of global } \\
\text { trade and trade } \\
\text { relations }\end{array}$ & 6 & 5 & $\begin{array}{l}\text { Economics of the } \\
\text { global industry }\end{array}$ & ISU \\
\hline $\begin{array}{l}\text { Business } \\
\text { strategy }\end{array}$ & $\begin{array}{l}\text { Competitive global } \\
\text { positioning }\end{array}$ & 6 & 5 & $\begin{array}{l}\text { Introduction to } \\
\text { retailing }\end{array}$ & UNCG \\
\hline Branding & $\begin{array}{l}\text { Global brand } \\
\text { marketing }\end{array}$ & 5 & 5 & $\begin{array}{l}\text { Multicultural and } \\
\text { multichannel } \\
\text { retailing }\end{array}$ & UNCG \\
\hline $\begin{array}{l}\text { Intercultural } \\
\text { communication }\end{array}$ & Workforce skills & 6 & 6 & $\begin{array}{l}\text { Global industry } \\
\text { issues }\end{array}$ & ISU \\
\hline $\begin{array}{l}\text { Small and } \\
\text { medium-sized } \\
\text { enterprises }\end{array}$ & $\begin{array}{l}\text { SMEs and the } \\
\text { industry in the } \\
\text { global economy }\end{array}$ & 5 & 9 & $\begin{array}{l}\text { Professional } \\
\text { development }\end{array}$ & SDSU \\
\hline $\begin{array}{l}\text { Product } \\
\text { development }\end{array}$ & $\begin{array}{l}\text { Role of product } \\
\text { development in } \\
\text { global industry }\end{array}$ & 6 & 9 & Apparel design & SDSU \\
\hline $\begin{array}{l}\text { Retail } \\
\text { landscape }\end{array}$ & $\begin{array}{l}\text { Assessing emerging } \\
\text { retail markets }\end{array}$ & 6 & 7 & Retail strategy & UNCG \\
\hline
\end{tabular}

When the modules were completed, they were introduced into existing related courses ranging from the sophomore to senior level. Comprising Phase III of the curriculum development process, each module was tested in a course at one of the three U.S. universities (see Table 1). The remainder of the article includes presentation and discussion of the results of the assessment of module effectiveness for developing students' global competence.

\section{Methodology}


A mixed methods approach was used to assess module effectiveness through an instrument that included open- and closed-ended questions (Creswell \& Plano Clark, 2007). With Institutional Review Board approval, a total of 172 participants, consisting of students at the three U.S. universities enrolled in the courses in which the modules were tested, were asked to complete a questionnaire two times (before and after module delivery).

Closed-ended questions were based on the CQ Scale, a scale used to assess CQ on four dimensions: metacognitive, cognitive, motivational, and behavioral (Dyne, Ang, \& Koh, 2008). The scale is based on Earley and Ang's (2003) theoretical conception of CQ as comprised four facets, each of which can be measured via the CQ scale:

- Metacognition (cognitive strategies to acquire and develop coping strategies);

- Cognition (knowledge about different cultures);

- Motivation (desire and self-efficacy); and

- Behavior (repertoire of culturally appropriate behaviors).

Twenty questions testing each of the four dimensions were included in the instrument (in both pre- and post-test), with responses recorded on a scale of $1=$ "Strongly Disagree" to $7=$ "Strongly Agree." Examples of questions included: I am conscious of the cultural knowledge I use when interacting with people with different cultural backgrounds, and I adjust my cultural knowledge as I interact with people from a culture that is unfamiliar to me (Metacognitive CQ); I know the legal and economic systems of other cultures, and I know the cultural values and religious beliefs of other cultures (Cognitive CQ); I enjoy interacting with people from different cultures, and I am confident that I can socialize with locals in a culture that is unfamiliar to me (Motivation CQ); and I vary the rate of my speaking when a cross-cultural situation requires it, and I change my nonverbal behavior when a cross-cultural situation requires it (Behavior CQ).

To determine whether the modules had an effect on students' CQ, a repeated measures experiment design was used, wherein each participant completed the survey two times, once before being introduced to the module and again after module activities were complete. A paired sample t-test was used to compare students' CQ before and after module exposure.

Eight open-ended questions, designed to facilitate reflection on the learning process and assess effectiveness of the educational materials, were included on the post-test. Examples of questions included: What did you like most about the experience? Why? What was the most challenging part of the experience? Why? and What, if anything, did you learn that will help you function as a professional in the global industry? Following standard protocol for analysis of qualitative data, responses to the open-ended questions by students at the three U.S. universities were typed, combined into a narrative, and analyzed for common categories and themes (Rubin \& Rubin, 1995; Spiggle, 1994). Thematic analyses were developed by a researcher at each of the three U.S. universities. Each researcher's analysis was then merged with the others to form a consistent whole that addressed the purpose of the study along with key issues identified in the 
relevant literature (Kvale, 1996). The resulting interpretation provides depth to the overall understanding of the extent to which the modules fostered students' global competence.

\section{Results}

Repeated Measures Experiment

Table 2 shows student CQ means measured in the pre- and post-tests and results of the paired sample t-test. The t-test results show that means of two CQ dimensions, Metacognitive CQ $(\mathrm{t}=2.016 ; \mathrm{p}=.045)$ and Cognitive CQ $(\mathrm{t}=4.640 ; \mathrm{p}=.001)$, increased significantly in the post-test when compared with the pre-test. The increase in Metacognitive CQ indicates that as a result of actively thinking about people and situations within diverse cultural backgrounds, students reported significantly greater cultural consciousness and awareness. The increase in Cognitive CQ indicates that students were more aware of cultural similarities and differences after exposure to the modules, having significantly higher "knowledge of norms, practices, and conventions in different cultural settings" (Dyne et al., 2008, p. 17).

Table 2. Pre- and post-test of Cultural Intelligence Dimensions and Results of Paired Sample t-test $(\mathrm{N}=172)$

\begin{tabular}{|c|c|c|c|c|c|c|c|}
\hline & \multicolumn{2}{|l|}{ Pre-test } & \multicolumn{2}{|c|}{ Post-test } & \multicolumn{3}{|c|}{ Paired sample t-test } \\
\hline & $\begin{array}{l}\text { Mean } \\
(\mathrm{SD})\end{array}$ & $\begin{array}{l}\text { Cronback's } \\
\text { Alpha }\end{array}$ & $\begin{array}{l}\text { Mean } \\
(\mathrm{SD})\end{array}$ & $\begin{array}{l}\text { Cronbach's } \\
\text { Alpha }\end{array}$ & Mean Diff & t-value & $\mathrm{p}$-value \\
\hline \multicolumn{2}{|c|}{$\begin{array}{l}\text { Cultural Intelligence } \\
\text { (CQ) }\end{array}$} & & & & & & \\
\hline Metacognitive & 4.96 & .79 & 5.14 & .89 & 0.17 & 2.016 & $.045^{*}$ \\
\hline CQ & $(1.05)$ & & $(1.01)$ & & & & \\
\hline \multirow[t]{2}{*}{ Cognitive CQ } & 3.49 & .87 & 3.95 & .82 & 0.46 & 4.640 & $.001 * *$ \\
\hline & $(1.12)$ & & $(1.07)$ & & & & \\
\hline Motivational & 5.24 & .85 & 5.22 & .89 & -0.02 & 0.257 & .798 \\
\hline CQ & $(0.96)$ & & $(0.93)$ & & & & \\
\hline \multirow{2}{*}{$\begin{array}{l}\text { Behavioral } \\
\mathrm{CQ}\end{array}$} & 4.46 & .86 & 4.64 & .87 & 0.18 & 1.789 & .076 \\
\hline & $(1.01)$ & & $(1.05)$ & & & & \\
\hline
\end{tabular}

NOTE: ${ }^{*} \mathrm{p}<.05, * * \mathrm{p}<.001$ 
Behavioral CQ also increased after completion of the modules (Table 2). However, the mean difference in the pre- and post-tests approached significance $(\mathrm{t}=1.789 ; \mathrm{p}=.076)$. This result implies that students perceived that their behaviors when interacting with people from different cultures changed somewhat after completing the modules. A possible explanation for this result is that not all learning modules included activities in which participants had an opportunity to engage in face-to-face communication with their culturally distinct counterparts. As a result, the students might have been unsure when rating their behaviors on items such as "I alter my facial expressions when a cross-cultural interaction requires it" and "I use pause and silence differently to suit different cross-cultural situations" (Dyne et al., 2008, p. 17).

Motivational CQ indicated a slight decrease (mean difference $=-0.02$ ) in the post-test. The finding indicates that students perceived that their "capability to direct attention and energy toward cultural differences" was similar in the pre- and post-test (Dyne et al., 2008, p. 17). This result does not mean that students were not motivated or interested in learning about other cultures. In fact, the opposite was true: student Motivation CQ had substantially higher means in both pre- and post-test in comparison with the three other dimensions of the CQ scale (Table 2). It is likely that the more students learned about cultural differences in beliefs, values, lifestyle, traditions, customs, and appropriate ways of doing business, the more they realized that there was more to learn about the world's different cultures. Students' confidence in rating their abilities to be successful in adapting to different cultural settings and/or communicating with people from different cultural backgrounds might not have increased on items such as "I am sure I can deal with the stresses of adjusting to a culture that is new to me" and "I am confident that I can socialize with locals in a culture that is unfamiliar to me" (Dyne et al., 2008, p. 17).

\section{Thematic Interpretation of Qualitative Data}

Three emergent themes-Acquiring Global Competence, Preparing for a Career in the Global Industry, and Learning as a Process - shed light on student experiences with completing the modules as well as how their opinions and perspectives on the outcomes of these experiences relate to the four CQ dimensions. For confidentiality, initials of pseudonyms are used in place of names.

Acquiring global competence Overall, students' responses indicated that the learning experiences provided by the modules helped them realize that when approaching cross-cultural situations, it was best to be open-minded about diverse perspectives and opinions that they might encounter. Many commented that it was crucial to avoid being judgmental about cultural difference, and to try to understand and accept others' way of thinking and doing things. For example, as one student explains,

People don't always think the same way you do, so you always need to try to understand their point of view even if you don't agree with it. It will help me go into a career with an 
open-mind. This experience will help me deal with issues, deadlines, relationships, etc. (AK)

When asked to reflect on their learning experiences, students repeatedly noted that, as a result of completing the modules, they learned to be respectful and patient when communicating with people from a different culture. The most frequent comment was that the modules helped them realize that it is important to listen to other people to understand their viewpoints.

I learned that to be patient and listen and try to interact with the different cultures is important. We all do not share same views but if we listen and be respectful, things will work out. (SO)

Student responses addressed both the Metacognitive and Behavioral dimensions of CQ when they observed that the modules were providing them with factual information about traditions, norms, and ways of life in different cultures and also helping them to become more respectful, patient, confident, open-minded, cooperative, and understanding when facing culturally different settings. They acknowledged that individuals with such qualities will be more likely to be successful both professionally and personally in a global environment.

By knowing a little more about other cultures we should be able to avoid offending others. We can be open-minded, cooperative, understanding, and respectful people. (LG)

Overall, students reported that as a result of completing the modules, they became more "cultural" and "globally aware."

I really enjoyed all of these activities because the world is getting smaller and it's getting to be more important for us to be able to interact with people and cultures all around the world. I feel a lot more prepared for that now. (IH)

Preparing for a career in the global industry Participants realized that the cultural knowledge and skills fostered by the modules were necessary for their future careers in the global industry. They commented on the importance of knowing traditions, customs, and rules of doing business with people from other cultures when developing the requisite professional skills.

I learned some of the different rules for doing business with individuals of other cultures. Some things I learned, I would have never known and it could have a negative impact on the business relationship. (LV)

Students acknowledged that working in the global industry is a team effort, with team members often located in different parts of the world depending on various supply chain 
functions. As the following response illustrated, this includes recognizing the importance of being a globally competent professional to be an effective member of a multinational team: "In this industry working together is crucial. The way almost everything is done in the industry is a global effort. Every culture is different as well, so you must always be aware of what you say, how you say it, and how you act" (WC). The need to be aware of how cultural difference plays out every day in the industry highlights the emergence of the Cognitive dimension of CQ within students' responses.

Four of the eight modules included activities that provided an opportunity for U.S. students to directly interact with their counterparts from universities located overseas. Depending on the module and the specific learning activity, students (i) worked in multicultural virtual teams to complete projects together, (ii) evaluated an entry into a domestic market proposed by international peers, or (iii) shared their views on the industry and career goals. In other words, they had the chance to learn together with culturally different peers by discussing, negotiating, and problem-solving industry related issues. The outcomes of these experiential learning activities were both knowledge- and skill-based, as the following responses indicate:

Learning how to complete overseas negotiations is very beneficial. This will allow me to be competitive in a global society. (HS) The most challenging part was realizing how difficult it is to launch a brand in a country that you do not have much experience with. It made me realize how important it is to work with locals who understand the culture. (BB)

Students greatly appreciated the opportunity to learn about other cultures from their peers abroad: "Seeing textiles and clothing students in different countries was something I hadn't seen before so it was very interesting" (LH). This experience was novel for most participants, as many of them had not been out of the United States or had the opportunity to interact with international peers to learn about their values, beliefs, and perspectives on the apparel industry as well as career aspirations. Participants commented that the unique opportunity to work together with international future industry professionals was the best way to learn how to communicate with culturally different counterparts. Student reflections indicated that being able to practice communication rather than reading or watching a video about it made the learning process more effective, engaging, and enjoyable.

I enjoyed being able to interact with people from different cultures. The best way to learn is to practice interaction. This was the most enjoyable part of the course work. (SR)

Learning as a process Completing the modules helped many of the students realize how little they knew about interacting with individuals from other cultures. Participants mentioned that they were surprised how much they were able to learn as a result of completing the learning activities that comprised the module: "I was surprised at all I learned. I knew I would learn something but I guess I had never anticipated gaining all this new insight into people and other 
cultures" (EN). Such reflections indicated that the modules were informative and fostered insight into cross-cultural interactions. It appears that engaging in and reflecting on the learning process helped participants re-evaluate their attitudes and behaviors toward others. "Although I feel pretty open-minded about other cultures, I realized that I wasn't as much as I thought I was and my pre-judged opinions were often wrong" (NB).

In many cases, responses suggested that the learning experience resulted in acquiring new knowledge, skills, and attitudes, and stimulating students' desires to continue expanding their awareness about other cultures. This highlights the role of the modules in promoting the Motivation dimension of CQ, in that participants often commented that the learning activities only scratched the surface about world cultures, and that there was a need to learn more to become a global citizen. In addition, students noted the importance of educating themselves about a new culture before traveling or communicating with members of the culture. As one commented, fostering one's knowledge about the culture conveyed interest and respect for its people.

I learned how to act with people from different cultures, that social norms are not the same in every culture, so if I am doing business as a professional in a different country, I must first do my research on it in order not to offend others. (PC)

Students noted that the format of the module activities - designed primarily to be hands-on, interactive, and engaging - contributed to the learning process and resulted in a better understanding and retention of information by keeping them interested and motivated.

I loved all the activities because they were hands on. I am a visual learner so these activities appealed to my learning style. (RH)

\section{Implications}

In addition to an increase in students' Metacognitive and Cognitive CQ dimensions, the student responses to open-ended questions about the overall experience touched on all four CQ dimensions, including Metacognitive, Cognitive, Behavior, and Motivation CQ. They frequently included words and phrases that suggested a high level of involvement with the material, including "very interesting,"“"eye-opener,"“'helped open my eyes,"“"really fun,"“"surprised," and "I really enjoyed...." Such responses indicated that the modules were successful in engaging students through active learning. This is often cited as the key to ensuring that the learning process facilitates meaningful and lasting outcomes (Meyers \& Jones, 1993; Nilson, 1998). Moreover, student responses to both open- and closed-ended questions demonstrated the effectiveness of the learning modules in (i) helping them to become more open-minded and respectful of cultural differences; (ii) foster patience, tolerance and understanding when interacting in cross-cultural environments; and (iii) being proactive in acquiring cultural 
knowledge. These outcomes are the primary components of global competence (Curran, n.d.; Hunter et al., 2006). Thus, the results of the pre- and post-tests indicated that the modules effectively fostered students' global competence by facilitating an understanding of industry challenges and practices from a global perspective.

Although this research contributes to the existing body of scholarship on developing global learning activities and assessing outcomes, there are limitations with regard to the development and testing of the modules that indicate the need for further research. For example, the exploratory use of the CQ instrument suggested that further item purification is needed, which could be achieved through repeated testing with different student samples. Because module testing occurred only in courses at the partner U.S. universities, use and assessment of the modules in other programs is needed to achieve a more comprehensive understanding of their effectiveness. Further integration of opportunities for face-to-face communication into all modules is also needed, as both closed- and open-ended responses indicated that this type of activity was critical to the learning process. Finally, the collaborative framework developed to create the modules should be applied with countries in addition to those included in this project to enhance the global scope of the modules.

It is hoped that the outcomes of this project will extend beyond its implementation, as students take the knowledge that they have gained, coupled with the experience of learning from others of diverse backgrounds, with them into the industry workforce. With the help of the modules, students' classroom experiences can equip them with the knowledge and experience they need to be professionals capable of forging relationships with representatives of foreign companies and working as part of a team within an environment that embraces difference. Ultimately helping to strengthen the industry's workforce, graduates who are globally competent will be cognizant of cultural differences and capable of synthesizing diverse perspectives in the workplace - a valuable skill as U.S. companies increasingly do business with foreign partners across the globe.

\section{References}

American Council on International Intercultural Education. (2005). Defining global competency. Retrieved January 23, 2007, from $\underline{\mathrm{http}: / / \text { www.acenet.edu. }}$

Biernacki, O., \& Waldorf, P. (1981). Snowball sampling: Problems and techniques of chain referral sampling. Sociological Methods \& Research, 10, 141-163.

Brislin, R., Worthley, R., \& Macnab, B. (2006). Cultural intelligence: Understanding behaviors that serve people's goals. Group \& Organization Management, 31(1), 40-55.

Cammett, M. (2006). Development and the changing dynamics of global production: Global value chains and local clusters in apparel manufacturing. Competition and Change, 10(1), $23-48$.

Commission on International Affairs. (2000). Expanding the international scope of universities. Washington, DC: National Association of State Universities and Land-Grant Colleges. 
Creswell, J., \& Plano Clark, V. L. (2007). Designing and conducting mixed methods research. Thousand Oaks, CA: Sage.

Curran, K. (n.d.). Global competencies that facilitate working effectively across cultures. Available at http://content.monster.com.sg/management/5808

DesMarteau, K. (2005). Country-by-country: Surges, declines, status quos. Apparel Magazine, 47(3), 16-19.

Dickerson, K. G. (1999). Textiles and apparel in the global economy. Upper Saddle River, NJ: Prentice Hall.

Dyne, L. V., Ang, S., \& Koh, C. (2008). Development and validation of the CQS: The Cultural Intelligence Scale. In S. Ang \& L. V. Dyne (Eds.), Handbook of cultural intelligence: Theory, measurement, and applications (pp. 16-38). Armonk, NY: M.E. Sharpe.

Earley, P. C. (2002). Redefining interactions across cultures and organizations: Moving forward with cultural intelligence research. Research in Organizational Behavior, 24, 271-299.

Earley, P. C., \& Ang, S. (2003). Cultural intelligence: Individual interactions across cultures. Stanford, CA: Stanford University Press.

Hanzl-Weiss, D. (2004). Enlargement and the textiles, clothing and footwear industry. The World Economy, 27(6), 923-945.

Harari, M. (1989). Internationalization of higher education: Effecting institutional change in the curriculum and campus ethos. Occasional Report Series on the Internationalization of Higher Education, Report \#1. Long Beach, CA: California State University, Center for International Education.

Harari, M. (1992). The Internationalization of the curriculum. In C. B. Klasek (Ed.), Bridges to the future: Strategies for internationalizing higher education (pp. 52-79). Pullman, WA: Washington State University's Center for International Development.

Hodges, N., \& Karpova, E. (2006). Employment in the U.S. textile and apparel industries: A comparative analysis of regional vs. national trends. Journal of Fashion Marketing and Management, 10(2), 209-226.

Hodges, N., \& Lentz, H. (2010). U.S. textile sector job loss: Implications for individuals, communities and industry. Journal of Fashion Marketing and Management, 14(1), 21-38.

Hunter, B., White, G. P., \& Godbey, G. C. (2006). What does it mean to be globally competent? Journal of Studies in International Education, 10(3), 267-285.

Knight, J. (1997). A shared vision? Stakeholders' perspectives on the internationalization of higher education in Canada. Journal of Studies in International Education, 1(1), 27-44.

Kvale, S. (1996). Inter-Views. Thousand Oaks, CA: Sage.

Meyers, C., \& Jones, T. B. (1993). Promoting active learning: Strategies for the college classroom. San Francisco, CA: Jossey-Bass.

Mittlehauser, M. (1997). Employment trends in textiles and apparel, 1973-2005. Monthly Labor Review, 120(8), 24-34. 
Ng, K.-Y., \& Earley, P. C. (2006). Culture + Intelligence: Old constructs, new frontiers. Group \& Organization Management, 31(1), 4-19. Nilson, L. B. (1998). Teaching at its best: A research-based resource for college instructors. Bolton, MA: Anker Publishing.

Norris, L. (2003). The human face of globalization: Plant closings and life transitions. Journal of Fashion Marketing and Management, 7(2), 163-181.

Oh, H., \& Suh, M. W. (2003). What is happening to the U.S. textile industry? Reflections on NAFTA and U.S. corporate strategies. Journal of Fashion Marketing and Management, $7(2), 119-137$.

Rivoli, P. (2009). The travels of a t-shirt in the global economy (2nd ed.). Hoboken, NJ: John Wiley.

Rubin, H. J., \& Rubin, I. S. (1995). Qualitative interviewing: The art of hearing data. Thousand Oaks, CA: Sage.

Scott, A. (2006). The changing global geography of low-technology, labor-intensive industry: Clothing, footwear, and furniture. World Development, 34(9), 1517-1536.

Spiggle, S. (1994). Analysis and interpretation of qualitative data in consumer research. The Journal of Consumer Research, 21(3), 491-503.

Thomas, D. C. (2006). Domain and development of cultural intelligence. Group \& Organization Management, 31(1), 78-99.

Thomas, D. C., \& Inkson, K. (2004). Cultural intelligence. San Francisco, CA: Berrett-Koehler Publishers Inc. 